\title{
Renal cytochrome P450 $\omega$-hydroxylase and epoxygenase activity are differentially modified by nitric oxide and sodium chloride
}

\author{
A.O. Oyekan, ${ }^{1}$ T. Youseff, ${ }^{1}$ D. Fulton, ${ }^{2}$ J. Quilley, ${ }^{3}$ and J.C. McGiff ${ }^{1}$ \\ ${ }^{1}$ Department of Pharmacology, New York Medical College, Valhalla, New York 10595, USA \\ 2Department of Pharmacology and Molecular Cardiobiology Program, Yale University, New Haven, Connecticut 06536, USA \\ ${ }^{3}$ Department of Cell Biology, University of Medicine and Dentistry of New Jersey, Stratford, New Jersey 08084, USA
}

Address correspondence to: A.O. Oyekan, Department of Pharmacology, New York Medical College, Grasslands Reservation, Valhalla, New York 10595, USA. Phone: (914) 594-4123; Fax: (914) 347-4956; E-mail: Bayo_Oyekan@NYMC.EDU.

Received for publication March 12, 1999, and accepted in revised form August 31, 1999.

Renal function is perturbed by inhibition of nitric oxide synthase (NOS). To probe the basis of this effect, we characterized the effects of nitric oxide (NO), a known suppressor of cytochrome P450 (CYP) enzymes, on metabolism of arachidonic acid (AA), the expression of $\omega$-hydroxylase, and the efflux of 20-hydroxyeicosatetraenoic acid (20-HETE) from the isolated kidney. The capacity to convert $\left[{ }^{14} \mathrm{C}\right] \mathrm{AA}$ to HETEs and epoxides (EETs) was greater in cortical microsomes than in medullary microsomes. Sodium nitroprusside $(10-100 \mu \mathrm{M})$, an NO donor, inhibited renal microsomal conversion of $\left[{ }^{14} \mathrm{C}\right] \mathrm{AA}$ to HETEs and EETs in a dose-dependent manner. 8-bromo cGMP $(100 \mu \mathrm{M})$, the cell-permeable analogue of cGMP, did not affect conversion of $\left[{ }^{14} \mathrm{C}\right] \mathrm{AA}$. Inhibition of NOS with $N^{\omega}$-nitro-L-arginine-methyl ester (L-NAME) significantly increased conversion of $\left[{ }^{14} \mathrm{C}\right] \mathrm{AA}$ to HETE and greatly increased the expression of $\omega$-hydroxylase protein, but this treatment had only a modest effect on epoxygenase activity. L-NAME induced a 4-fold increase in renal efflux of 20-HETE, as did L-nitroarginine. Oral treatment with $2 \%$ sodium chloride $(\mathrm{NaCl})$ for 7 days increased renal epoxygenase activity, both in the cortex and the medulla. In contrast, cortical $\omega$-hydroxylase activity was reduced by treatment with $2 \% \mathrm{NaCl}$. Coadministration of $\mathrm{L}-\mathrm{NAME}$ and $2 \% \mathrm{NaCl}$ decreased conversion of $\left[{ }^{14} \mathrm{C}\right] \mathrm{AA}$ to HETEs without affecting epoxygenase activity. Thus, inhibition of NOS increased $\omega$-hydroxylase activity, CYP4A expression, and renal efflux of 20-HETE, whereas $2 \% \mathrm{NaCl}$ stimulated epoxygenase activity.

J. Clin. Invest. 104:1131-1137 (1999).

\section{Introduction}

Nitric oxide (NO) is a multifunctional molecule secreted by many cell types that mediates diverse physiological processes, contributing to the regulation of vascular tone, platelet function, neurotransmission, host defense mechanisms, cytostasis, and cytotoxicity $(1,2)$. These multiple functions of NO reflect its affinity for hemoproteins, the principal targets of NO. Thus, NO affects the activity of heme-containing enzymes. These include NO synthase (NOS) $(3,4)$, enzymes of the mitochondrial electron transport system (2), cyclooxygenase (COX) $(5,6)$, and the cytochrome P450-1A1 (CYP1A1), CYP2B1 $(7,8)$, CYP3C $(9)$, and CYP4A $(10,11)$ families. Several potential mechanisms have been suggested to explain NO-induced inactivation of CYP, such as liberation of heme from CYP proteins (12), inhibition of CYP protein synthesis (8), NO reaction with superoxide to form peroxynitrite that effects nitration of critical amino acids (13), and binding of NO to the heme moiety of CYP, forming nitrosyl-heme adducts, with subsequent oxidation of free thiols in CYP enzymes (14). The coordinate operation of several of the above mechanisms (which vary with experimental conditions and the tissues under study) are thought to serve as the basis for the ability of NO to inhibit CYP enzymes such as $\omega$-hydroxylase, which synthesizes 20-hydroxyeicosatetraenoic acid (20HETE), the principal renal eicosanoid (15).
Most of the studies examining NO-CYP interactions have been conducted in the liver $(7,9,10,11)$. However, CYP is not limited to the liver - it is expressed at many sites. Indeed, the specific activity of renal CYP isoforms that metabolize arachidonic acid (AA) is greater than that of liver isoforms (16). Considering the wide distribution and the remarkable activity of CYP enzymes in the kidney (17), coupled with the fact that of all vascular beds NO has the most prominent influence on the renal vasculature (18), the study of NO-CYP interactions in the kidney is important for understanding the regulation of renal hemodynamic and excretory mechanisms.

The CYP pathway of AA metabolism forms HETEs and eicosatrienoic acids, or epoxides (EETs), which exhibit a variety of biological effects, including mitogenicity, vasoactivity, and modulation of ion channel activity (17). 20-HETE has been reported to be an essential component of tubuloglomerular feedback (19) and renal autoregulation (20), as well as a modulator of transport in the medullary thick ascending limb (21) and proximal tubules (22). The production of 20-HETE is inhibited by $\mathrm{NO}(10)$, indicating the importance of NO-CYP interactions to the control of renal function. To underscore the critical nature of NO-CYP interactions, marked perturbations of renal function were produced by inhibiting NOS and thereby eliminating the suppressant effects of NO on 20-HETE synthesis (23). One or more epoxides 
may function as endothelium-derived hyperpolarizing factors $(24,25)$, mediating NO-independent effects of endothelium-dependent vasodilator agents (26). Removal of the tonic inhibitory influence of $\mathrm{NO}$ can uncover the expression of an epoxide-dependent vascular mechanism $(25,26)$. In view of the prominent and diverse renal actions of 20-HETE and the epoxides, it can be said that the interactions of NO and CYP have a major effect on renal vascular and excretory mechanisms.

This study was designed to characterize interactions of $\mathrm{NO}$ and CYP in terms of the effects of NO on conversion of AA to CYP-derived AA products in the rat kidney. We first verified that NO inhibited CYP activity with sodium nitroprusside, an NO donor. We then determined levels of CYPderived AA products formed by renal microsomes obtained from rats in which NO synthesis was inhibited (renal microsomes are associated with increased content of the CYP4A enzyme family that generates 20-HETE). Inhibition of NOS increased CYP-dependent conversion of AA by renal microsomes. We extended these findings to the intact kidney, and showed that inhibition of NOS increased efflux of 20HETE from the isolated rat kidney. We also found that increased intake of sodium chloride $(\mathrm{NaCl})$ selectively enhanced the activity of renal epoxygenases, thereby increasing conversion of AA to EETs and confirming the essential findings of the in vivo study of Makita et al. (27).

\section{Methods}

Materials. Indomethacin was dissolved in 50\% ethanol. $N^{\omega_{-}}$ nitro-L-arginine-methyl ester (L-NAME), L-nitro-arginine (LNA), phenylephrine, sodium nitroprusside, and 8-bromoguanosine 3', $5^{\prime}$-cyclic monophosphate (8BrcGMP) were dissolved in distilled water. (All preceding reagents were obtained from Sigma Chemical Co., St. Louis, Missouri, USA.) We obtained $\left[{ }^{14} \mathrm{C}\right] \mathrm{AA}$ from NEN Life Science Products Inc. (Boston, Massachusetts, USA); it was stored in ethanol at $-70^{\circ} \mathrm{C}$ until use. The Western blotting kit for rat CYP4A was obtained from Amersham International (Amersham, United Kingdom), and was stored at $4^{\circ} \mathrm{C}$ until use.

Animals. Adult male Sprague-Dawley $(270 \pm 5 \mathrm{~g})$ or Wis$\operatorname{tar}(\sim 400 \mathrm{~g})$ rats were obtained from Charles River Laboratories Inc. (Wilmington, Massachusetts, USA). The animals were placed in a room with lighting that was adjusted to produce a normal day-night cycle (illuminated from 0800 to 2000 hours). They were maintained on a standard diet of Purina chow and were allowed ad libitum access to water and food before experiments.

Protocol. Sprague-Dawley rats were allocated randomly into groups ( $n=5$ per group) that received L-NAME (70 $\mathrm{mg} / \mathrm{kg}$ orally for 10 days) in $250 \mathrm{~mL}$ tap water containing $16.2 \mathrm{mg}$ (1 tablet) of sodium saccharin (CVS/pharmacy, Seattle, Washington, USA) Control rats received tap water containing sodium saccharin but not L-NAME. Systolic blood pressure of awake rats was measured by tail-cuff plethysmography using a Natsume KN-210 manometertachometer system (Peninsula Laboratories Inc., Belmont, California, USA). In some experiments, the effect of L-NAME on epoxygenase activity was evaluated. In this case, rats received $2 \% \mathrm{NaCl}$ (wt/vol) ad libitum for 7 days according to the protocol reported by Makita et al. (27), a regimen that produced a selective increase in epoxygenase activity. Another group of rats received $2 \% \mathrm{NaCl}$ for
7 days and L-NAME as above. At the end of the treatment period, microsomes were prepared from the kidneys of the rats in each group; microsomes from each group were separated into 2 parts for evaluation of AA metabolism and for immunodetection of CYP4A protein.

Preparation of renal microsomes. Sprague-Dawley rats were anesthetized intraperitoneally with pentobarbital (65 $\mathrm{mg} / \mathrm{kg}$ ). The abdominal cavity was opened and the aorta was tied above the renal arteries. Ice-cold normal saline $(0.9 \% \mathrm{NaCl})$ was flushed through the aorta into the kidneys. The kidneys were removed and separated into cortex and medulla. Each fraction was homogenized in 0.01 M Tris (hydroxymethyl) aminomethane containing 0.25 M sucrose ( $\mathrm{pH}$ 7.4). Microsomes were prepared by standard differential centrifugation techniques. Protein concentration was determined by the Bradford method using a kit from Bio-Rad Laboratories Inc. (Hercules, California, USA), with BSA as the standard.

AA metabolism. Microsomal suspensions ( $0.3 \mathrm{mg}$ protein) from cortex or medulla were incubated with $\left[{ }^{14} \mathrm{C}\right] \mathrm{AA}$ $(0.2-0.4 \mu \mathrm{Ci} ; 3 \mu \mathrm{M})$ and cold $\mathrm{AA}(7 \mu \mathrm{M})$ in the presence of $\mathrm{NADPH}(1 \mathrm{mM})$ and indomethacin $(10 \mu \mathrm{M})$, in a total reaction volume of $1 \mathrm{~mL}$ for 30 minutes at $37^{\circ} \mathrm{C}$. Data from cortex and medulla were pooled to give total renal microsomal conversion of $\left[{ }^{14} \mathrm{C}\right] \mathrm{AA}$ to $\mathrm{CYP}$ metabolites. These reactions were performed in microsomal suspensions from 4 groups of rats ( $n=5$ in each group): (a) untreated control rats; (b) rats that received $2 \% \mathrm{NaCl}$ in drinking water for 7 days; (c) rats that received L-NAME $(70 \mathrm{mg} / \mathrm{kg})$ in drinking water for 10 days; and (d) rats that received L-NAME $(70 \mathrm{mg} / \mathrm{kg}$ for 10 days $)+2 \% \mathrm{NaCl}$ for 7 days

Enzyme activity (represented as specific activity in Table 1) was calculated from percentage conversion of $\left[{ }^{14} \mathrm{C}\right] \mathrm{AA}$ in individual microsomal preparations relative to the mean total enzyme activity in each group of rats.

In other experiments, the effect of NO on AA metabolism was evaluated by adding sodium nitroprusside (10 $\mu \mathrm{M}, 30 \mu \mathrm{M}$, and $100 \mu \mathrm{M}$, final concentration) or 8 BrcGMP $(100 \mu \mathrm{M}$, final concentration) or vehicle (distilled water) to microsomal preparations from control rats $(n=5)$. Reaction mixtures were then incubated for 30 minutes. Different concentrations of sodium nitroprusside were added to aliquots of microsomal samples obtained from different rats.

In all cases, metabolites were extracted with acidified ethyl acetate ( $\mathrm{pH} \mathrm{3-4)}$ and subjected to reverse-phase HPLC. The elution profile of the radioactive metabolites of AA was detected and counted using an on-line radioactive detector (Radiomatic Instruments and Chemical Co., Meriden, Connecticut, USA). The identity of each metabolite was confirmed by its comigration with authentic standards during HPLC or by gas chromatography/mass spectrometry (GC/MS).

Endogenous formation of 20-HETE in isolated perfused kidney. Rat kidneys were perfused according to a previously described procedure (28). Rats were anesthetized intraperitoneally with $65 \mathrm{mg} / \mathrm{kg}$ pentobarbital, and the right kidney was exposed by midline laparotomy. The right renal artery was cannulated via the mesenteric artery to avoid interruption of blood flow, and then perfused with oxygenated $\left(5 \% \mathrm{O}_{2} / 5 \% \mathrm{CO}_{2}\right)$ Krebs buffer $(\mathrm{pH} 7.4)$ at $37^{\circ} \mathrm{C}$. The right kidney from Sprague-Dawley rats was removed 
and perfused at constant flow of $8-10 \mathrm{~mL} / \mathrm{min}$ to obtain a basal perfusion pressure of $75-90 \mathrm{mmHg}$. Either vehicle or L-NAME $\left(10^{-4} \mathrm{M}\right)$ was added to the perfusate. Perfusate was collected under basal perfusion (usually 5-10 minutes after perfusion started) and again 20 minutes after LNAME was added, when a stable perfusion pressure was usually obtained. To determine whether perfusion pressure has an effect on release of 20 -HETE, L-NA $\left(5 \times 10^{-5} \mathrm{M}\right)$ was substituted for L-NAME in Wistar rats. After 10 minutes, renal perfusion pressure was elevated to $175-200 \mathrm{mmHg}$ with phenylephrine $\left(1-2 \times 10^{-7} \mathrm{M}\right.$ for L-NA-treated kidneys and $7.5 \times 10^{-7} \mathrm{M}$ for control kidneys).

After total lipid extraction of $10 \mathrm{~mL}$ of perfusate with ethyl acetate, reverse-phase HPLC separation of eicosanoids was carried out using a 1050A system from Hewlett Packard (Palo Alto, California, USA). HPLC fractions were collected every minute, and separate fractions containing HETEs (especially 19-HETE and 20-HETE), which eluted at 6.5-7.1 minutes, were collected for quantitation by selected ion monitoring and negative chemical ionization-GC/MS (NCIGC/MS) as we described previously (29). Selected ion monitoring was used to record ion abundancies using a mass spectrometer (HP 5989A) at $m / z 391$ and 393, which correspond to endogenous 20-HETE and the internal standard, respectively.

Immunodetection of CYP4A. The immunodetection procedure was performed according to a protocol provided by Amersham International. The method uses an antirat CYP4A primary antibody raised in sheep that binds specifically to the immobilized CYP4A isoenzyme. The isoenzyme, localized to renal microsomes (prepared as described herein), was immobilized on nitrocellulose membranes. Electrophoretic separation (SDS-PAGE) was done using a Mini-PROTEAN II dual slab cell (BioRad Laboratories Inc.), followed by transfer to nitrocellulose membranes. Immunodetection consisted of using the primary antibody to CYP4A isoenzyme, a biotinylated secondary antibody (anti-sheep Ig), a streptavidin horseradish peroxidase conjugate, and enhanced chemiluminescence Western blotting detection reagents. As positive control, liver microsomes from clofibrate-treated rats were used. Autoradiographs were quantitated by densitometric scanning using SigmaScan software (Jandel Scientific Software, Palo Alto, California, USA).

Statistical analysis. All data are expressed as mean \pm SEM, and were analyzed using ANOVA followed by the Newman-Keuls test when appropriate. In other cases, the Student's $t$ test for unpaired data was used to determine significant difference between control and treated groups. In all cases, $P<0.05$ was regarded as significant.

\section{Results}

Effects of sodium nitroprusside on AA metabolism. Renal microsomes from control rats incubated with $\left[{ }^{14} \mathrm{C}\right] \mathrm{AA}$ in the presence of NADPH $(1 \mathrm{mM})$ and indomethacin $(10$ $\mu \mathrm{M})$ produced HETEs, DHTs (diols), and EETs (epoxides) with retention times of 10.5-11.2 minutes, 8.5-9.3 minutes, and 15.2-16.3 minutes, respectively (Figure 1). Because DHTs are hydration products of EETs, the amounts of both compounds were pooled to quantify total epoxygenase metabolites of AA.
Control enzyme activity was $0.29 \pm 0.04$ (epoxygenase: $0.02 \pm 0.01$; $\omega$-1-hydroxylase: $0.27 \pm 0.03) \mathrm{nmol} / \mathrm{mg}$ protein per 30 minutes. Sodium nitroprusside $(10-100 \mu \mathrm{M})$, an NO donor, inhibited renal microsomal production of HETEs and epoxygenase metabolites (expressed as percent of control) in a dose-dependent manner (Figure 2). The maximal inhibitory concentrations of sodium nitroprusside for both groups of metabolites were similar, but threshold inhibitory concentrations differed. Thus, in renal microsomes incubated with the lowest concentration of sodium nitroprusside $(10 \mu \mathrm{M})$, production of HETEs was slightly but significantly reduced to $84 \pm 7 \%$ $(P<0.05)$ of control, in contrast to a marked reduction in the production of DHTs and EETs $(50 \pm 3 \%$; $P<0.01)$. At the highest concentration used $(100 \mu \mathrm{M})$, sodium nitroprusside reduced the production of both groups of metabolites to the same extent: production of HETEs was reduced to $26 \pm 7 \%(P<0.01)$ of control, and that of DHTs and EETs was reduced to $30 \pm 6 \%(P<0.01)$ of control (Figure 2). In contrast to the marked inhibition produced by sodium nitroprusside, $100 \mu \mathrm{M}$ 8BrcGMP (the cell-permeable analogue of cGMP, the second messenger of NO), had no effect on the production of either of these groups of CYP-AA metabolites. (Figure 2).
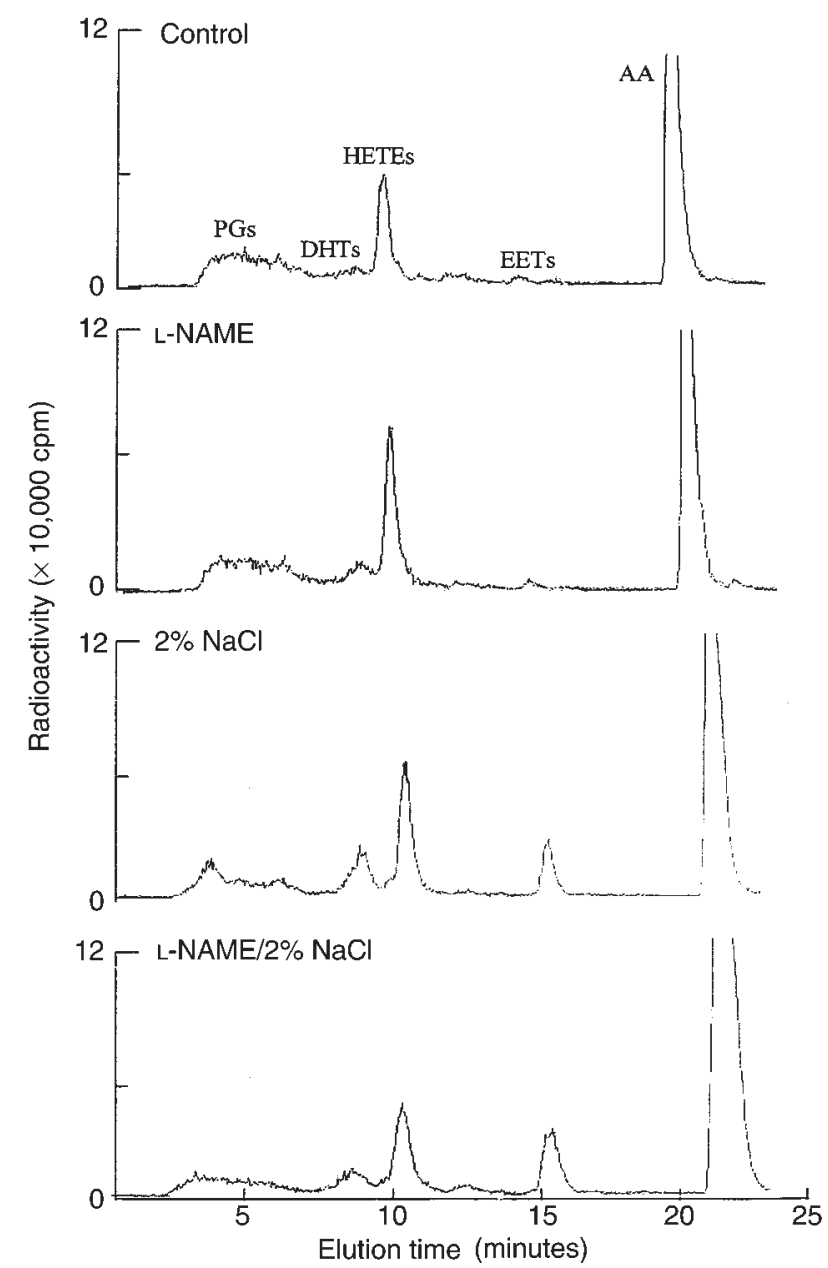

\section{Figure 1}

Representative reverse-phase HPLC chromatograms of $\left[{ }^{14} \mathrm{C}\right] \mathrm{AA}$ metabolites formed by renal microsomes in untreated control rats (top) and rats treated with L-NAME or $\mathrm{NaCl}$ only (middle) or L-NAME and $2 \% \mathrm{NaCl}$ (bottom). 


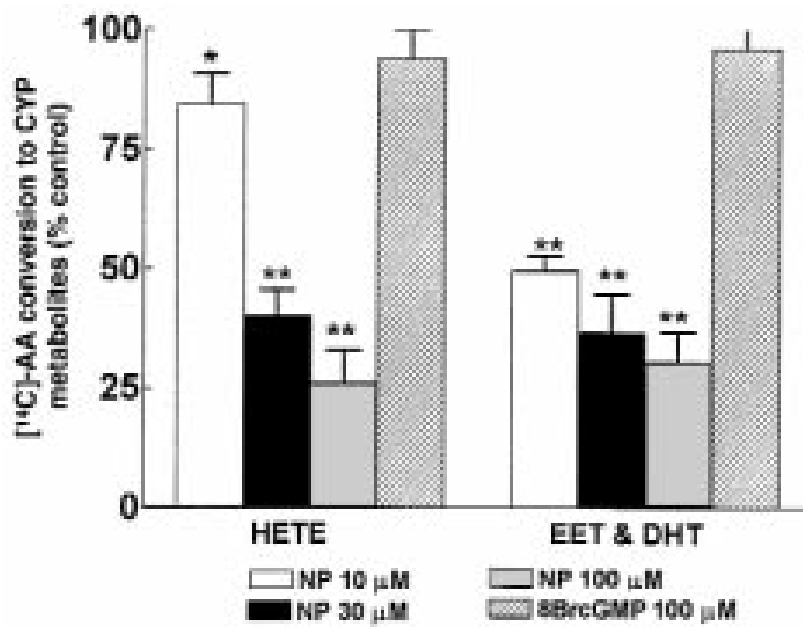

Figure 2

Concentration-dependent inhibition by sodium nitroprusside of production of HETEs, DHTs, and EETs in rat renal microsomes. Microsomes $(300 \mu \mathrm{g})$ were incubated with NADPH $(1 \mathrm{mM})$ and indomethacin $(10 \mu \mathrm{M})$ in the presence or absence of sodium nitroprusside $(10 \mu \mathrm{M}, 30 \mu \mathrm{M}$, and $100 \mu \mathrm{M})$ or $8 \operatorname{BrcGMP}(100 \mu \mathrm{M})$ for 30 minutes at $37^{\circ} \mathrm{C}$. Metabolites were analyzed by HPLC. Control enzyme activity was $0.29 \pm 0.04 \mathrm{nmol} / \mathrm{mg}$ protein per 30 minutes. Results are presented as mean $\pm \mathrm{SEM} ; n=5$ separate experiments $\left(n=3\right.$ for 8 BrcGMP). ${ }^{*} P<0.05,{ }^{*} P<0.01$. NP, sodium nitroprusside.

Effects of L-NAME on renal microsomal CYP-AA metabolism. Because sodium nitroprusside, an NO donor, inhibited the production of HETEs, DHTs, and EETs (Figure 2), these experiments were designed to examine the role of endogenous NO on CYP-AA metabolism by inhibiting its synthesis. The results of these experiments are presented in Table 1 and Figure 3. In microsomes prepared from rats treated with L-NAME for 10 days, total CYP-AA enzyme activity was $0.36 \pm 0.06 \mathrm{nmol} / \mathrm{mg}$ protein per 30 minutes (HETEs: $0.34 \pm 0.04$; EETs: $0.02 \pm 0.01$ ), compared with a value of $0.26 \pm 0.04 \mathrm{nmol} / \mathrm{mg}$ protein per 30 minutes (HETEs: $0.24 \pm 0.03$; EETs: $0.02 \pm 0.01$ ) in rats from littermates not treated with L-NAME. After 10 days of treatment with L-NAME, conversion of AA to HETEs increased from $29 \pm 3 \%$ to $38 \pm 4 \%(n=5 ; P<0.05)$ in microsomes from control rats $(n=5)$, whereas conversion of AA to DHTs and EETs was unaffected. Rats treated with L-NAME developed hypertension as systolic blood pressure rose to $183 \pm 9 \mathrm{mmHg}$, compared with $118 \pm 4$ $\mathrm{mmHg}$ in control rats. In microsomes prepared from rats treated with $2 \% \mathrm{NaCl}$ for 7 days $(n=5)$, conversion of AA to DHTs and EETs was markedly enhanced, as expected $(17 \pm 2 \% ; P<0.01)$, increasing more than 8 -fold from $2 \pm$ $1 \%$ in microsomes from control rats that received tap water $(n=5)$ (Figure 3$)$. In contrast, conversion of HETEs was not changed significantly by treatment with $2 \% \mathrm{NaCl}$ ( $22 \pm 4 \%$ vs. $28 \pm 3 \%$ in controls; $n=5)$. However, in rats that received both $2 \% \mathrm{NaCl}$ and L-NAME $(n=5)$, there was a dramatic reduction in AA conversion to HETEs, from $22 \pm 4 \%$ to $11 \pm 1 \%(P<0.05)$; total conversion of AA to DHTs and EETs was unchanged $(2 \% \mathrm{NaCl}$ alone: $17 \pm 2 \%$; L-NAME $+2 \% \mathrm{NaCl}: 17 \pm 2 \%$ ) (Figure 3 ).

In Table 1, cortical and medullary microsomal conversion of $\left[{ }^{14} \mathrm{C}\right] \mathrm{AA}$ to HETEs and EETs is expressed in terms of specific activity ( $\mathrm{pmol} / \mathrm{mg}$ protein per 30 minutes). Under control conditions, cortical microsomes exhibited a greater capacity to convert AA to HETEs and EETs than did medullary microsomes. Microsomes from each zone demonstrated increased capacity of CYP enzymes to convert AA to EETs and HETEs after inhibition of NO synthesis by L-NAME. The inclusion of $2 \% \mathrm{NaCl}$ in drinking water for 10 days greatly elevated conversion of AA to EETs, whereas it reduced the capacity of cortical microsomes to convert AA to HETEs. This capacity underwent a further decline when L-NAME was given along with $2 \% \mathrm{NaCl}$. Combined treatment with L-NAME and $2 \% \mathrm{NaCl}$ also depressed the capacity of medullary microsomes to convert AA to HETEs. However, L-NAME and $2 \% \mathrm{NaCl}$ given together did not affect the ability of either cortical or medullary microsomes to convert $\left[{ }^{14} \mathrm{C}\right] \mathrm{AA}$ to EETs; this capacity remained high and similar to that produced by $\mathrm{NaCl}$ treatment alone.

Figure 1 shows the HPLC chromatograms depicting the effects of either L-NAME or $2 \% \mathrm{NaCl}$ on CYP-dependent AA metabolism. The HETE fractions were subjected to GC/MS analysis to evaluate the profile of the HETEs produced in microsomes after L-NAME treatment. The increase in production of HETEs after inhibition of NO production was selective for 20-HETE - none of the subterminal HETEs (16-, 17-, 18-, and 19-HETE) were detected by selected ion monitoring and NCI-GC/MS.

Effect of L-NAME on the expression of CYP4A protein. As shown in Figure 4, Western blot analysis indicates that CYP4A protein (mol wt: $51 \mathrm{kDa}$ ) is constitutively expressed in renal microsomes of control rats (lanes 2 and 3), and is inducible in liver microsomes from clofibrate-treated rats (positive control, lane 1). In microsomes from rats treated with L-NAME for 10 days (lanes 4,5 , and 6), the expression of CYP4A protein increased by $39 \pm 5 \%(P<0.05)$, increasing the blot density from

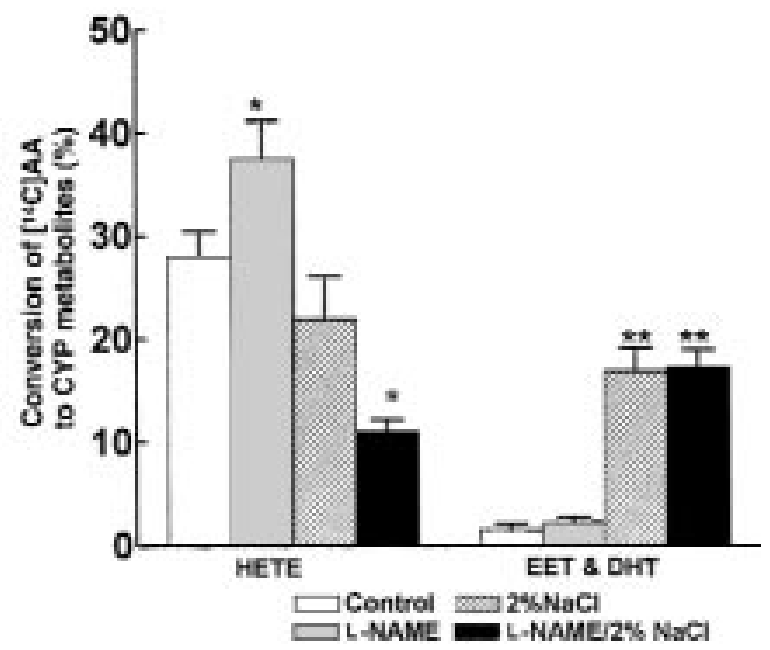

Figure 3

Effect of L-NAME on conversion of $\left[{ }^{14} \mathrm{C}\right] \mathrm{AA}$ to HETEs, DHTs, and EETs. Microsomes from control rats and rats treated with L-NAME and/or $2 \%$ $\mathrm{NaCl}$ were incubated with $\left[{ }^{14} \mathrm{C}\right] \mathrm{AA}$ in the presence of $\mathrm{NADPH}$ and indomethacin. Values are mean \pm SEM obtained from renal microsomes prepared from 5 rats. CYP enzyme activity in rats treated with L-NAME was $0.36 \pm 0.06 \mathrm{nmol} / \mathrm{mg}$ protein per 30 minutes. ${ }^{*} P<0.05 \mathrm{vs}$. control. 
$(180 \pm 55) \times 10^{3}$ intensity units $($ control $)$ to $(294 \pm 39) \times$ $10^{3}$ intensity units in rats that received L-NAME treatment (4b), an increase in protein that corresponds to the $30 \%$ increase in AA conversion to HETEs (Figure 3).

Effect of L-NAME and L-NA on endogenous production of 20HETE in perfused rat kidney. In kidneys obtained from Sprague-Dawley rats treated with L-NAME $\left(10^{-4} \mathrm{M}\right)$, perfusion pressure increased from $96 \pm 6 \mathrm{mmHg}$ to $143 \pm 10$ $\mathrm{mmHg}$. Efflux of 20-HETE increased 4-fold, to $3.6 \pm 0.7$ $\mathrm{ng} / \mathrm{min}$ from a basal (control) value of $0.9 \pm 0.5 \mathrm{ng} / \mathrm{min}$. To address the effect of increased perfusion pressure on renal 20-HETE release independently of inhibition of NO formation, perfusion pressure was elevated to similar values in L-NA-treated $\left(5 \times 10^{-5} \mathrm{M} ; n=5\right)$ kidneys obtained from Wistar rats. In the presence of L-NA, the concentration of phenylephrine that was required to elevate perfusion pressure from $87 \pm 2 \mathrm{mmHg}$ (control; $n=$ 5) to $214 \pm 8 \mathrm{mmHg}$ was several-fold less $\left(2-4 \times 10^{-7} \mathrm{M}\right)$ than that required to elevate perfusion pressure $(200 \pm 3$ $\mathrm{mmHg})$ in control kidneys $\left(7.5 \times 10^{-7} \mathrm{M}\right)$. The release of 20-HETE from kidneys treated with L-NA was approximately 4-fold greater than that from untreated kidneys $(1.42 \pm 0.30 \mathrm{ng} / \mathrm{min}$ vs. $0.33 \pm 0.13 \mathrm{ng} / \mathrm{min}$, respectively; Figure 5) at equivalent perfusion pressures.

\section{Discussion}

NO plays a pivotal role in directing the metabolism of AA, not only by COX but also by CYP. NO interacts with COX, usually stimulating its activity to increase the formation of prostanoids $(5,6)$. The inducible form of NOS (iNOS) has been implicated in many of the features of endotoxin shock and has provided an explanation for the associated impairment in liver metabolism of xenobiotics (9) produced by immunostimulants, because NO inhibits CYP enzymes. These findings are supported by reports that NO donors inhibit the CYP-dependent renal vasodilator effect of AA in the rat (30), presumably by suppressing formation of EETs. The capacity of NO to inhibit 20-HETE generation by $\omega$-hydroxylases is a major component in the renal vasodilator response to $\mathrm{NO}(10)$; it accomplishes this by removing the tonic inhibitory effect of 20-HETE on calcium-activated potassium channels in renal arterioles (11).

\section{Table 1}

\begin{tabular}{lcccc}
\hline & CONTROL & L-NAME & $\mathrm{NaCl}$ & L-NAME+NaCl \\
HETEs - Cortex & $54.5 \pm 6.5$ & $77.8 \pm 11.5^{\mathrm{A}}$ & $29.7 \pm 3.3^{\mathrm{A}}$ & $15.4 \pm 4.2^{\mathrm{A}}$ \\
Medulla & $32.4 \pm 2.2^{\mathrm{C}}$ & $50.5 \pm 2.5^{\mathrm{A}, \mathrm{C}}$ & $34.6 \pm 7.7^{\mathrm{N}}$ & $22.3 \pm 4.4^{\mathrm{A}}$ \\
EETs & & & & \\
Cortex & $1.2 \pm 0.4^{\mathrm{C}}$ & $1.6 \pm 0.5^{\mathrm{B}}$ & $25.6 \pm 6.3^{\mathrm{B}}$ & $22.6 \pm 2.8^{\mathrm{B}}$ \\
Medulla & $0.28 \pm 0.2^{\mathrm{C}}$ & $0.45 \pm 0.14^{\mathrm{A}, \mathrm{C}}$ & $19.2 \pm 4.3^{\mathrm{B}}$ & $23.5 \pm 5.4^{\mathrm{B}}$
\end{tabular}

Enzyme activity is expressed as specific activity in $\mathrm{pmol} / \mathrm{mg}$ protein $/ 30 \mathrm{~min}$. ${ }^{A} P<$ 0.05 , $\mathrm{B} P<0.01 \mathrm{~L}-\mathrm{NAME}$ versus Control or $\mathrm{NaCl}$ versus Control or L-NAME+NaCl versus L-NAME. ${ }^{C} P<0.05$ Medulla versus Cortex. $\left[{ }^{14} \mathrm{C}\right] \mathrm{AA}$ metabolism in renal microsomes obtained from untreated rats (Control; $n=5$ ) or those treated with $\mathrm{L}$ NAME ( $70 \mathrm{mg} / \mathrm{kg}$ orally for 10 days; L-NAME, $n=5$ ), $2 \% \mathrm{NaCl}$ in drinking water for 7 days $(\mathrm{NaCl} ; n=5$ ) or combined treatment with L-NAME and $2 \% \mathrm{NaCl}$ (L$\mathrm{NAME}+\mathrm{NaCl} ; n=5) .\left[{ }^{14} \mathrm{C}\right] \mathrm{AA}$ metabolism was evaluated separately for HETEs and EETs in cortical and medullary microsomes incubated with $\left[{ }^{14} \mathrm{C}\right] \mathrm{AA}(0.2-0.4 \mu \mathrm{Ci} ; 3$ $\mu \mathrm{M})$ and cold $\mathrm{AA}(7 \mu \mathrm{M})$.

The importance of NO modulation of 20-HETE synthesis to renal function was evident in the depression of renal hemodynamics and altered sodium excretion produced by disinhibiting 20-HETE formation in response to suppression of NO synthesis by L-NAME (23). The essential findings of this study, that renal microsomal CYP-dependent AA metabolism is enhanced by inhibition of NO synthesis (Table 1), is in accord with our in vivo and in vitro studies. The importance of NO-CYP interactions to renal function is evident when considering modulation of tubuloglomerular feedback, which acts as "both sensor and effector of total salt and volume homeostasis" (31). In response to increased $\mathrm{NaCl}$ intake, generation of $\mathrm{NO}$ is enhanced (32), and production of vasoconstrictor 20HETE by the afferent glomerular arteriole is suppressed (11). Tubuloglomerular feedback is blunted, i.e., $\mathrm{NaCl}$ delivery to the nephron is increased. Contrary to this, when NO synthesis is reduced by decreased dietary salt, tubuloglomerular feedback is potentiated as 20-HETE production is increased in the effector unit, the afferent arteriole.

We evaluated the effects of NO on CYP enzyme activity in the rat kidney with NO donors and inhibitors of NOS in order to modify CYP-dependent AA metabolism. We verified that NO inhibited CYP, and then addressed

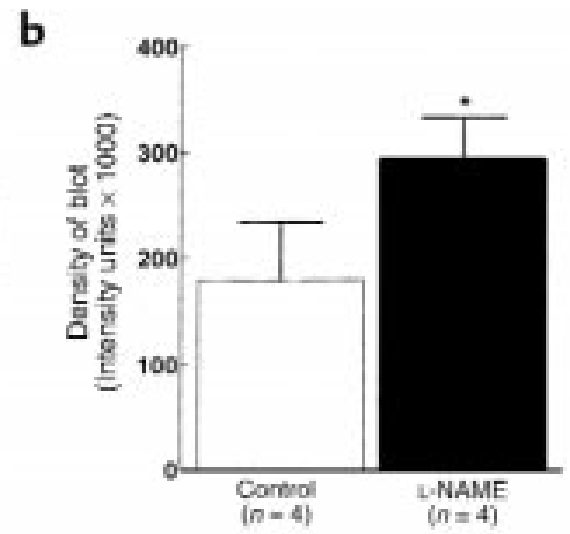

\section{Figure 4}

(a) Representative Western blot showing the expression of CYP4A protein ( $51 \mathrm{kDa}$ mol wt) in renal microsomes prepared from normal rats (control, lanes 2 and 3) or in those treated with L-NAME (lanes 4, 5, and 6). Samples of liver microsomes treated with clofibrate provided the positive control (lane 1). The immunoblotting procedure used anti-rat CYP4A primary antibody from sheep. (b) Density of the blot as analyzed by densitometric scanning. ${ }^{*} P<0.05$, L-NAME $(n=4)$ vs. control $(n=4)$. 
the effects of inhibition of NOS both in vivo and in vitro on the generation of CYP-AA metabolites. We established that NO tonically inhibits $\omega$ hydroxylase based on these observations: (a) sodium nitroprusside dosedependently inhibited conversion of exogenous AA to HETEs by renal microsomes; (b) treatment of rats with L-NAME to inhibit synthesis of NO resulted in an increased capacity to convert AA to the HETEs (Table 1) associated with increased expression of CYP4A protein (Figure 3); and (c) treatment of the isolated rat kidney with either L-NA or L-NAME increased efflux of 20HETE several-fold (Figure 4). These observations are consistent with a tonic inhibitory effect by $\mathrm{NO}$ on both activity and expression of $\omega$-hydroxylase.

As shown in Figure 2 and as recently reported by Alonso-Galicia et al. (10), the NO donor sodium nitroprusside concentration-dependently inhibited conversion of AA by CYP enzymes, an effect that was unrelated to the ability of $\mathrm{NO}$ to stimulate guanylate cyclase (inasmuch as 8BrcGMP had no effect) (Figure 2). In experiments designed to demonstrate that inhibition of NO synthesis increased CYP-dependent AA product formation, chronic administration of L-NAME increased the capacity of renal microsomes to produce CYP-AA metabolites. Production of HETEs was increased to a greater degree in cortical than in medullary microsomes (Table 1). Suppression of CYP-AA metabolism by NO may not be solely the result of a direct interaction of $\mathrm{NO}$ with CYP, because chronic inhibition of NO synthesis increased the expression of the CYP4A protein (Figure 3), indicating that $\mathrm{NO}$ acts at more

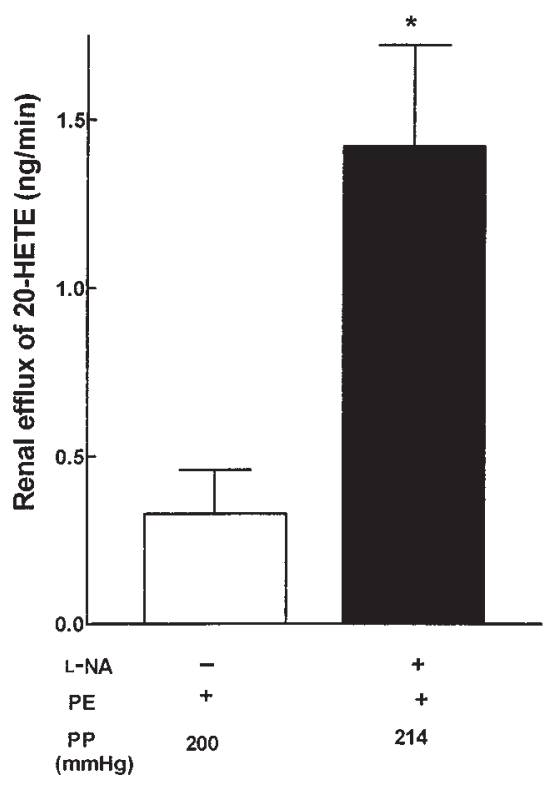

\section{Figure 5}

Concentration of 20-HETE in renal effluents collected after addition of phenylephrine (PE; $\left.7.5 \times 10^{-7} \mathrm{M}\right)$ alone (L-NA-) or after combined addition of phenylephrine $\left(2-4 \times 10^{-7} \mathrm{M}\right)$ and L-NA $\left(5 \times 10^{-5} \mathrm{M}\right)$ to Krebs buffer perfusing isolated kidneys of Wistar rats. Perfusates collected were subjected to HPLC fractionation and quantified by GC/MS analysis as described in Methods. Data are presented as mean \pm SEM. ${ }^{*} P<0.05$ vs. L-NA-. PP, perfusion pressure after addition of PE with $(+)$ or without $(-)$ L-NA added to the perfusate. than 1 site in the CYP pathway - perhaps at a transcription site, as reported for NO-mediated inhibition of mitogenesis and proliferation in vascular smooth muscle (33).

Our findings that renal microsomal epoxygenase activity is enhanced more than 10 -fold in response to increased intake of $\mathrm{NaCl}$ in the drinking water confirm the important study of Makita et al. (27). Moreover, inhibition of epoxygenase led to elevated blood pressure in rats, suggesting that deficient EET production, particularly 5,6 EET can result in salt-sensitive hypertension (27). In contrast to enhancement of epoxygenase activity by high salt intake, HETE production by cortical microsomes was diminished, a finding in agreement with the study of Stec et al. (34).

The capacity of the cortex to metabolize AA with CYP enzymes (Table 1) exceeded that of the medulla, largely because of the heavy concentration of $\omega$-hydroxylase and $\omega$-1-hydroxylase activity in the predominant tubular segment (the proximal tubule) in this renal zone (35). Furthermore, the cortical vasculature, particularly preglomerular blood vessels, possesses a high capacity to generate 20 -HETE $(36,37)$. These differences are reflected in the greater capacity of cortical as compared with medullary microsomes to transform AA to HETEs (Table 1 ). In response to $2 \% \mathrm{NaCl}$, conversion of $\mathrm{AA}$ by $\omega$-hydroxylase to HETEs in medullary microsomes was unaffected, whereas it was decreased in cortical microsomes, as noted. On the other hand, in rats with a high intake of $\mathrm{NaCl}$, the addition of L-NAME inhibited AA conversion to HETEs, an effect that was striking in cortical microsomes, with HETE production falling by more than $70 \%$. Decreased 20-HETE synthesis in response to combined administration of high $\mathrm{NaCl}$ and L-NAME may reflect dissociation between renal sites of major activity of the hydroxylases ( $\omega$-hydroxylases and $\omega$-1hydroxylases) and NO synthases. NOS activity is highest in the medulla (38), whereas CYP activity is highest in the cortex (Table 1). All NOS isoforms - neural, inducible, and endothelial - are found in the renal medulla (39). Moreover, medullary nNOS is involved in control of blood pressure, particularly in response to high $\mathrm{NaCl}$ intake (40). The inhibitory activity of $\mathrm{NO}$ (and the effects of its removal) on CYP AA metabolism should depend on the ratio of activities of epoxygenases and $\omega$-hydroxylases to NOS in cortical vs. medullary microsomes. Results in Table 1 are consistent with this interpretation, because percent increases of medullary microsomal conversion of AA to HETEs and EETs are elevated over the levels reached in cortical microsomes in response to either L-NAME or L-NAME with $2 \% \mathrm{NaCl}$. However, answers to questions raised by the adverse effects on HETE production caused by combined LNAME and $2 \% \mathrm{NaCl}$ should be based on direct measurements by GC/MS of CYP-derived AA products from endogenous sources of AA, thereby avoiding concerns regarding limits on the availability of $\left[{ }^{14} \mathrm{C}\right] \mathrm{AA}$.

In the whole organ (the isolated perfused rat kidney), inhibition of NO synthesis with either L-NA or L-NAME increased the release of 20-HETE into the renal effluent. These results are consistent with the elimination of the inhibitory influence of $\mathrm{NO}$ on $\omega$-hydroxylase activity, and are in agreement with the data obtained from microsomes 
in rats maintained on normal salt and treated chronically with L-NAME. This effect of inhibition of NOS on increasing renal efflux of 20-HETE cannot be attributed to differences in renal perfusion pressure between groups, because kidneys in the experimental and the control groups were both exposed to equivalent perfusion pressures, induced by phenylephrine to prevent such influences. In addition, the increase in renal efflux of 20-HETE induced by L-NA or L-NAME cannot be attributed to the increased expression of CYP4A protein that was observed in rats treated chronically with L-NAME (Figure 3), because these kidneys were exposed to L-NA or L-NAME for no more than 1 hour, making it unlikely that these effects were related to increased protein synthesis.

We conclude that it is possible to manipulate the activities of renal epoxygenase and $\omega$-hydroxylase activities differentially, because only EET production is increased by increasing $\mathrm{NaCl}$ intake, whereas $\omega$-hydroxylase activity is increased primarily by inhibition of $\mathrm{NO}$ formation.

\section{Acknowledgments}

This work was supported by National Institutes of Health grants RO1 HL-59884 and PPG HL-34300-13 to J.C. McGiff, and RO1 HL-25394 and Grant-In-Aid $9750303 \mathrm{~N}$ to A.O. Oyekan. The authors thank Melody Steinberg for editorial assistance and Jennifer Brown for help in preparing the manuscript.

1. Moncada, S., Palmer, R.M.G., and Higgs, E.A. 1991. Nitric oxide: physiology, pathophysiology and pharmacology. Pharmacol. Rev. 43:109-142.

2. Nathan, C. 1992. Nitric oxide is a secretory product of mammalian cells. FASEB J. 6:3051-3064.

3. Hurshman, A.R., and Marletta, M.A. 1995. Nitric oxide complexes of inducible nitric oxide synthase: spectral characterization and effects on catalytic activity. Biochemistry. 34:5627-5634.

4. Griscavage, J.M., Habbs, A.J., and Ignarro, L.J. 1995. Negative modulation of nitric oxide synthase by nitric oxide and nitroso compounds. $A d v$. Pharmacol. 34:215-234.

5. Salvemini, D., et al. 1993. Nitric oxide activates cyclooxygenase enzymes. Proc. Natl. Acad. Sci. USA. 90:7240-7244.

6. Ferraz, J.G.P., et al. 1997. Induction of cyclooxygenase 1 and 2 in the rat stomach during endotoxemia: role in resistance to damage. Gastroenterology. 113:195-204.

7. Wink, D.A., et al. 1993. Inhibition of cytochrome $\mathrm{P} 450$ by nitric oxide and a nitric oxide releasing agent. Arch. Biochem. Biophys. 300:115-123.

8. Stadler, J., et al. 1994. Inhibition of cytochromes P4501A by nitric oxide. Proc. Natl. Acad. Sci. USA. 91:3559-3563.

9. Khatsenko, O.G., Gross, S.S., Rifkind, A.B., and Vane, J.R. 1993. Nitric oxide is a mediator of the decrease in cytochrome P450-dependent metabolism caused by immunostimulants. Proc. Natl. Acad. Sci. USA. 90:11147-11151

10. Alonso-Galicia, M., Drummond, H.A., Reddy, K.K., Falck, J.R., and Roman, R.R. 1997. Inhibition of 20-HETE production contributes to the vascular responses to nitric oxide. Hypertension. 29:320-325.

11. Sun, C.-W., et al. 1998. Nitric oxide 20-hydroxyeicosatetraenoic acid interaction in the regulation of $\mathrm{K}+$ channel activity and vascular tone in renal arterioles. Circ. Res. 83:1069-1079.

12. Kim, Y.M., Bergonia, H.A., Muller, C., Pitt, B.R., Watkins, W.D., and Lancaster, J.R., Jr. 1995. Loss and degradation of enzyme-bound heme induced by cellular nitric oxide synthesis. J. Biol. Chem. 270: 5710-5713.

13. Mehl, M., Daiber, A., Herold, S., Shoun, H., and Ullrich, V. 1999. Peroxynitrite reaction with heme proteins. Nitric Oxide. 3:142-152.

14. Minamiyama, Y., et al. 1997. Irreversible inhibition of cytochrome P450 by nitric oxide. J. Pharmacol. Exp. Ther. 283:1479-1485.

15. McGiff, J.C., and Quilley, J. 1999. 20-HETE and the kidney: resolution of old problems and new beginnings. Am. J. Physiol. 46:R607-R623.

16. Schwartzman, M.L., Abraham, N.G., Carroll, M.A., Levere, R.D., and McGiff, J.C. 1986. Regulation of arachidonic acid metabolism by cytochrome P450 in rabbit kidney. Biochem. J. 238:283-290.

17. McGiff, J.C. 1991. Cytochrome P-450 metabolism of arachidonic acid. Annu. Rev. Pharmacol. Toxicol. 31:339-369.

18. Navar, L.G. 1998. Integrating multiple paracrine regulators of renal microvascular dynamics. Am. J. Physiol. 274:F433-F444.

19. Zou, A.-P., et al. 1994. Effect of P450 $\omega$-hydroxylase metabolites of arachidonic acid on tubuloglomerular feedback. Am. J. Physiol. 266:F934-F941

20. Zou, A.-P., et al. 1994. Inhibition of renal vascular 20-HETE production impairs autoregulation of renal blood flow. Am. J. Physiol. 266:F275-F282.

21. Escalante, B., Erlij, D., Falck, J.R., and McGiff, J.C. 1991. Effect of cytochrome $\mathrm{P} 450$ arachidonate metabolites on ion transport in rabbit kidney loop of Henle. Science. 251:799-802.

22. Ribeiro, C.M., Dubay, G.R., Falck, J.R., and Mandel, L.J. 1994. Parathyroid hormone inhibits $\mathrm{Na}(+)-\mathrm{K}(+)$-ATPase through a cytochrome P450 pathway. Am. J. Physiol. 266:F497-F505.

23. Oyekan, A.O., and McGiff, J.C. 1998. Functional response of the rat kidney to inhibition of nitric oxide synthesis: role of cytochrome P450derived arachidonate metabolites. Br. J. Pharmacol. 125:1065-1073.

24. Campbell, W.B., Gebremedhin, D., Pratt, P.F., and Harder, D.R. 1996. Identification of epoxyeicosatrienoic acids as endothelium-derived hyperpolarizing factors. Circ. Res. 78:415-423.

25. Fulton, D., McGiff, J.C., and Quilley, J. 1998. Pharmacological evaluation of an epoxide as the putative hyperpolarizing factor mediating the nitric oxide-independent vasodilator effect of bradykinin in the rat heart. J. Pharmacol. Exp. Ther. 287:497-503.

26. Fulton, D., McGiff, J.C., and Quilley, J. 1991. Contribution of NO and cytochrome $\mathrm{P} 450$ to the vasodilator effect of bradykinin in the rat kidney. Br. J. Pharmacol. 107:722-725.

27. Makita, K., et al. 1994. Experimental and/or genetically controlled alterations of the renal microsomal cytochrome P450 epoxygenase induce hypertension in rats fed a high salt diet. J. Clin. Invest. 94:2414-2420.

28. Oyekan, A.O., McGiff, J.C., and Quilley, J. 1991. Cytochrome P450dependent vasodilator responses to arachidonic acid in the isolated perfused kidney of the rat. Circ. Res. 68:958-965.

29. Oyekan, A.O., Balazy, M., and McGiff, J.C. 1997. Renal oxygenases: differential contribution to vasoconstriction induced by endothelin-1 and angiotensin II. Am. J. Physiol. 273:R293-R300.

30. Oyekan, A.O. 1995. The suppression by lipopolysaccharide of cytochrome P450-dependent renal vasodilation in the rat is mediated by nitric oxide. Eur. J. Pharmacol. 277:123-132.

31. Harris, R.C. 1996. The macula densa: recent developments. J. Hypertens. 14:815-822

32. Wilcox, C.S., and Welch, W.J. 1996. TGF and nitric oxide: effects of salt intake and salt-sensitive hypertension. Kidney Int. Suppl. 55:S9-S13.

33. Garg, U.C., and Hassid, A. 1989. Nitric oxide-generating vasodilators and 8-bromo-cyclic guanosine monophosphate inhibit mitogenesis and proliferation of cultured rat vascular smooth muscle cells. J. Clin. Invest. 83:1774-1777.

34. Stec, D.E., Trolliet, M.R., Krieger, J.E., Jacob, H.J., and Roman, R.J. 1996. Renal cytochrome P4504A activity and salt sensitivity in spontaneously hypertensive rats. Hypertension. 27:1329-1336.

35. Omata, K., Abraham, N.G., and Schwartzman, M.L. 1992. Renal cytochrome P-450-arachidonic acid metabolism: localization and hormonal regulation in SHR. Am. J. Physiol. 262:F591-F599.

36. Okita, J.R., Castle, P.J., and Okita, R.T. 1993. Characterization of cytochromes $\mathrm{P} 450$ in liver and kidney of rats treated with di-(2-ethylhexyl)phthalate. J. Biochem. Toxicol. 8:135-144.

37. Wang, M.-H., et al. 1999. Contribution of cytochrome P450 4A1 and $4 \mathrm{~A} 2$ to vascular 20-hydroxyeicosatetraenoic acid synthesis in rat kidneys. Am. J. Physiol. 276:F246-F253.

38. Zou, A.P., and Cowley, A.W. 1997. Nitric oxide in renal cortex and medulla: an in vivo microdialysis study. Hypertension. 29:194-198.

39. Mattson, D.L., and Bellehumeur, T.G. 1996. Neural nitric oxide synthase in the renal medulla and blood pressure regulation. Hypertension. 28:297-303.

40. Mattson, D.L., and Higgins, D.J. 1996. Influence of dietary sodium intake on renal medullary nitric oxide synthase and L-NAME hypertension. Hypertension. 27:688-692. 